\title{
Complexity of catering business operations and its impact on food safety
}

Castro, Dixie $\bowtie$

Occidental Mindoro State College, Philippines (jundixcastro@hotmail.com)

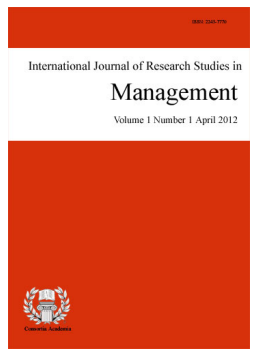

Accepted: 4 January 2021 Online ISSN: 2243-7789

OPEN ACCESS

\section{Abstract}

The increasing complexity in catering industry today requires more innovative approaches and standard practices to better prioritize and allow for rapid integration of new specific developments. Preventing food safety barriers should be every caterer's top priority as it can ruin a catering business since food safety is the ultimate component for sustainable development. The study aimed to assess the off-premises business operation in Occidental Mindoro. This study used a descriptive quantitative method through survey questionnaire. A total of 210 off-premises catering employees from licensed and non-licensed catering business holding supervisory and non-supervisory level were recruited to participate the study which they actually work in all of the positions including management, food preparation and food service areas. It was revealed that the off-premises catering business operations in Occidental can face various risks because of non-compliance to food safety certification assessed by the certified auditor. The employees of off-premises catering between licensed and non-licensed business operation demonstrated consistent knowledge on food safety such as health and hygiene requirement, maintenance and pest management but failed to follow from required standards in off-site operations. The evaluation of food safety practices among different caterers determined the specific safety programs and interventions they could applied in their own catering business operation. The researcher proposed series of recommendations: To improve food safety practices, local authorities need to have an annual audit of the practices and require extensive certification requirements. The management of off-premises catering business operation may focus their efforts and commitment on food safety and recruitment process to ensure employees who have a strong work ethics.

Keywords: catering business; food safety; management operations; personal practices 


\section{Complexity of catering business operations and its impact on food safety}

\section{Introduction}

The changing lifestyle of people has changed their eating patterns and food consumption outside home. It is every human right to have access to safe and quality food because safer food contributes to less illness and conforming to international food safety standards will contribute to a safer life and customer satisfaction. It is also been rooted to the integration and consolidation of food industries, current dietary patterns of people, the globalization of the food trade and human mobilization are modifying and leveling up the system of food production, distribution and consumption. The complexity of catering business operation has resulted in unanticipated food borne risks with pervasive effects human on lives.

Food safety is a foremost responsibility of every food service operators including the off-premises caterers with the intention of providing meals to huge people every day. The people behind providing meals should ensure that food satisfies the food law requirement, and that controls system are integrated and being applied to their operation to prevent, eliminate and reduce risks to consumers (Food Safety Act, section 13). Food service establishments are major settings for food borne pathogen exposure due to wide array of food displays and of high food consumption outside homes. Catering an event offsite can be a great business for a food enthusiast yet food safety remains a critical requirement, and it posts major challenges when offsite. Food safety is basically not the priority of every catering business, but the focus is on presentation and service purposes. Food safety must be considered in the operation to avoid food borne illness.

Off-premises catering are a type of business that is serving food at a location away from the caterer's food production facility like a freestanding commissary that has a kitchen facility used exclusively for food preparation and served at other locations where there is no existing kitchen facility at the location where the food is served. It means that this type of food service is providing great number of box lunches to people and therefore large number of lives is at risks. The assurance of these people to receive safe food is primarily based on the safe food practices of the food handlers. Food safety research of Strohbehn (2014) has focused on the importance of workforce training and education, as it is believed that training and knowledge alone do not assure safe food handling by employees.

The increasing complexity in catering industry today requires more innovative approaches and standard practices to better prioritize and allow for rapid integration of new specific developments. Preventing food safety barriers should be every caterer's top priority as it can ruin a catering business since food safety is the ultimate component for sustainable development there is a positive impact of this complexity on food safety that focuses primarily on human health and safety being mandated by the law to respond on their responsibility as caterers. The creation of relevant and existing food safety laws and regulations is necessary to establish a credible system and build the confidence of customers. It is crucial that these businesses obliged to follow and being adopted the food safety laws and regulations to prevent and manage food safety issues. The catering industry need an updated food safety standard that addresses the issues involved in achieving food safety objectives. Standards must be based on building risk assessment competence.

Off-premises catering became complex in different aspect of food production and service and thereby increased problems in the management of food safety; likewise its culture and the external business climate in which the business operates influence the effective implementation of food safety systems. This requires the manipulation and embedding of food safety management systems yet truly difficult because no one approach fits all. Manning (2018) different intervention strategies should be applied in the form of policies, enforcement, and education are deployed to reduce risks of potential food borne hazards (Lee, 2013). Caterers can have a chance to properly select, prioritize, and implement food safety interventions and incorporate multiple strategies to 
enhance effectiveness and efficiency in their production and services.

There are safety systems which have been adopting for quality food safety management standard. The combine standards of ISO 22000: 2005 in the Food Services. Organization for Standardization (ISO) to introduce ISO 22000:2005 (ISO 2011) would be the caterer's advantage because it is based upon the principle that food safety is best ensured through embedding Hazard Analysis and Critical Control Point (HACCP) in their own system. HACCP provides a formal method for food businesses to manage the safety of food as it is prepared and processed within the business. The standards adopted should be internationally recognized with satisfying result that includes better risk management, better operational efficiency and customer satisfaction. Therefore, addressing food safety in a systemic and sustainable way will contribute toward increasing sales, reducing costs, minimizing risks and repeat patronage.

Occidental Mindoro is one of the biggest employers for food establishments including off-premises catering business. The province has eight municipalities with 23 licensed off-premises caterers who are largely contributing to economic sustainability and employment opportunities to Mindorenos. Not all off-premises caterers in Occidental Mindoro understand the roles they play, such as addressing food safety with focus on basic hygienic practices at times of purchasing, preparing and serving food people to safeguard the health and that of the wider community. They should make food safety as their prime motive in doing the business, establishing and implementing effective food safety practices and should be based on the standards to ensure that all employees and suppliers operate responsibly.

The study pointed out the food safety management of off-premises licensed and non-licensed catering business in different municipality of the province. It will provide insights to food operators to implement and adopt the right food safety system for their operation. Standard compliance, whether they are regulatory or scheme-specific, will always be challenging. Therefore, it is always important that management continues to stay abreast of food safety standards, which will ultimately enable them to stay ahead of the curve and definitely safeguard the health and safety of its customers.

\subsection{Objectives of the study}

The study aimed to assess the off-premises business operation in Occidental Mindoro. The specific objectives of the study are to: determine the profile of respondents in terms of sex, age, number of years in service, employment status, position, and food safety certification; to determine the business profile in terms of years in service of the business, type of management operation, total meals served per function, number of function per month, events usually catered, food safety certification and local government certification; determine the practices of off-premise catering operations in terms of management operation and personal practices on food Safety, test the significant difference in the safety practices between licensed and non-licensed off-premise catering business, and lastly to propose a food safety training plan intended for off-premise catering employees.

\section{Methods}

\subsection{Research design}

This study used a descriptive quantitative method through survey questionnaire. The researcher also had observations and interviews to gather a breadth and depth of information from selected employees of off-premises catering both licensed and non-licensed to evaluate the complexity of the catering business operations and its impact on food safety. The researcher had given opportunity to immediately observe the employees and some of the business operational practices and did interviews and used a structured interview guide question. 


\subsection{Participants}

For the scope of this study, 210 off-premises catering employees from licensed and non-licensed catering business holding supervisory and non-supervisory level were recruited to participate which they actually work in all of the positions including management, food preparation and food service areas. One (1) supervisor and four (4) employees each catering operations was the target of the study. According to DTI there are twenty (23) licensed caterers in eight municipalities in Occidental Mindoro namely: San Jose, Magsaysay, Rizal, Calintaan, Sablayan, Sta. Cruz, Mamburao and Abra De Ilog. Same number of respondents was also considered for non-licensed business with one observation schedule and interview. Participation in the study was voluntary.

\subsection{Instrument}

An observation form and a modified version of the food safety checklist was adopted and mainly used to evaluate food safety management practices of off- premises catering operations. The food safety checklist was used as a guide in operating food business. The pilot testing results were also used to make modifications to the forms and develop the questionnaire consisting of two phases. The first phase includes the use of structured in-depth interviews to determine food safety management practices and the possible barriers in safe food handling of foodservice employees. Initial interview is important in order to get the exact information from the respondents before the questionnaire is made. It is one of the methods of qualitative research and with structured interview every aspect of the research is planned before data are collected. Second phase was focused on administering of a questionnaire to evaluate food safety practices in an off-premises catering operation. The survey was adjusted according to the type of respondents and to be more appropriate for off premise employees. Questions specific to off -premises catering services was applied. Respondent made their ratings on 20 items using a Likert scale, (4) Strongly Agree, (3) Agree, (2) Disagree, and (1) Strongly Disagree. Questions were based to employee's perception on food safety practices both management and self.

\subsection{Data gathering procedure}

Researcher had visited the operation twice, with the same employee each time. Each visit consisted of an hour observation period during the operation. To avoid employees' nervousness as the researcher obviously watched them overtime, several steps were taken: (1) to discreetly record observations, the researcher used cellphone to have an actual picture and later record it according to their moves; (2) researcher initiated non-formal small talk to employees after their tasks. Interviews were customized depending on the observed employees' behaviors. Before the conduct of observation and interview, a consent forms the managers were used. Researcher was able to validate further with follow up questions as required based on the particular circumstances of the operation.

\subsection{Data analysis}

Observational data from 23 off-premises catering operation were analyzed qualitatively through its verbal comments and work activities. Compliance rates and other forms on food safety standards were calculated based on Mean and Standard Deviation to determine the compliance of every off-premises catering business whether licensed or non-licensed in terms of management operation and practices. Frequencies for all variables. Also, SPSS was used for principal component factor analyses and ANOVA for independent variables such as gender, age, number of years in catering operations, employment status and food safety training attended and for business profile such as type of food service operation, years in service, type of management operation, total meals served per function, number of functions per month, events usually catered, food safety certification and local government certification. Data of food safety management practices has been divided into two separate variables as management and personal practices. Interviews were recorded and analyzed based on analysis of interview transcripts until the main result has been achieved. 


\section{Results and discussion}

Table 1 presents respondent's profile. Of the 210 off-premises catering employees and respondents in this research, male constituted 55.8 percent and slightly higher than half, where female having 43.7 percent. The result indicates that catering operations in Occidental Mindoro employed performance work team mostly males. Respondents were mostly 18-25 years of age and considered young individuals with 41.4 percent other age bracket between 26-35 (30.5 percent) 36-55 (24.8 percent) and 56 and above (3.3 percent) Catering managers stated that hiring young catering employees can bring fresh perspective and a different way of thinking to their job. Most young workers are eager to learn, build their experience and apply their skills in the workforce. They hire young individuals depending on the nature of their job, while older workers bring a level of experience and sheer knowledge that cannot be taught. Workforces are becoming increasingly diverse in age demographics, creating professional environments that are rich with experience and maturity as well as youthful exuberance. The number of years in service by the staff off -premises catering business varied from below one year with 34.8 percent, two to five years with 49.0percent, six to ten years having 14.3 percent and to more than 10 years of 1.9 percent.

Table 1

Profile of the respondents

\begin{tabular}{|c|c|c|c|}
\hline Employee Profile & & $F$ & $\%$ \\
\hline \multirow[t]{2}{*}{ Sex } & Male & 120 & 57.1 \\
\hline & Female & 90 & 42.9 \\
\hline \multirow[t]{4}{*}{ Age } & $18-25$ years old & 87 & 41.4 \\
\hline & $26-35$ years old & 64 & 30.5 \\
\hline & $36-55$ years old & 52 & 24.8 \\
\hline & 56 years and above & 7 & 3.3 \\
\hline \multirow[t]{4}{*}{ Number of Years in Service } & below 1 year & 75 & 34.8 \\
\hline & $2-5$ years & 103 & 49.0 \\
\hline & $6-10$ years & 30 & 14.3 \\
\hline & above 10 years & 4 & 1.9 \\
\hline \multirow[t]{3}{*}{ Employment status } & Full-time & 75 & 35.7 \\
\hline & Part-time & 80 & 38.1 \\
\hline & On call & 55 & 26.2 \\
\hline \multirow[t]{7}{*}{ Position } & Restaurant Manager & 10 & 4.9 \\
\hline & Restaurant Supervisor & 6 & 2.8 \\
\hline & Cook & 17 & 8.1 \\
\hline & Food Preparation Assistant & 65 & 31.0 \\
\hline & Sanitation Technician & 2 & 1.0 \\
\hline & Service Person & 95 & 45.2 \\
\hline & Administrative Person & 15 & 7.0 \\
\hline \multirow[t]{2}{*}{ Have you been certified in food safety training? } & Yes & 32 & 15.2 \\
\hline & No & 178 & 84.8 \\
\hline
\end{tabular}

Most of the employees worked as part timers with 35.7 percent, catering businesses typically hire part time employees for the reason of an hourly wage and can schedule them for whatever number of hours the company desires. Full time workers of 38.1 percent ranked only second as to the employment status of the business who has been working forty hours a week and able to receive different benefits and on call workers with only 26.2 percent. Companies hire full time, part-time and on-call individuals in order to carry out essential duties to make the organization thrive.

Catering business mostly employed service person with 45.2 percent, the result showed that they use a higher number of servers for the different events so each guest will receive prompt and personalized services. Also, food preparation assistant of 31.0 percent who will work on the quality of prepared foods for guest's satisfaction and cook of 8.1 percent who oversees the operation of the kitchen and do the actual preparation of food. Most employees had not undertaken any formal food safety certification training as indicated in the 
Castro, D.

frequency result of 84.8 percent and only 15.2 percent have been certified in food safety training. Most of the food establishments are not training their employees and managers on food safety systems, making them lack food safety knowledge to employees and managers (Karaman et al., 2012) explained that lack of management training resulted in lack of knowledge on the use of food safety systems.

Unfortunately, most of the employees had not received food safety training that is vital in all food handlers. The training can help them better understand issues that may occur and how they can best respond to those inevitable problems. Training of food handlers on hygiene is quite necessary. Yardimc1 et al. (2015) found that the status of food safety in foodservice institutions can be enhanced through food safety training courses for food handlers on food safety, periodic audit of staff knowledge on food safety practices, and increased salary. In turkey, the same case has been attributed to workers having low knowledge on food safety because of lack of training provided to them likewise training employees on food safety practices has been shown to be one of the most important programs that food service establishments can implement. However, results also provide evidence that traditional approaches used to educate, and train employees may not be particularly effective, and new behavior-based approaches that include food safety education as part of the culture of the organization need to be developed (Neil et al., 2013). These individuals pursue good performance through shared goals and a strong sense of accountability and trust among its members.

Table 2

Frequency distribution of the business profile

\begin{tabular}{llcc}
\hline \multicolumn{1}{c}{ Business Profile } & & $F$ & $\%$ \\
\hline Years in Service of the Business & Less than 1 year & 9 & 4.3 \\
& $1-5$ years & 68 & 32.4 \\
& 6-10 years & 61 & 29.0 \\
& above 10 years & 72 & 34.3 \\
\hline Type of Management Operation & self-operated & 150 & 71. \\
& contract management & 60 & 28.6 \\
\hline Total Meals Served per Function & below 100 & 10 & 4.7 \\
& 101 -200 & 110 & 52.4 \\
& above 200 & 90 & 42.9 \\
\hline Number of Function Per Month & below 10 & 67 & 31.9 \\
& $11-20$ & 115 & 54.8 \\
& above 20 & 28 & 13.3 \\
\hline Events Usually Catered & Wedding & 53 & 25.2 \\
& Birthdays & 79 & 37.6 \\
& Seminar/Convention & 61 & 29.1 \\
& Others & 17 & 8.1 \\
\hline Food Safety Certification & With & 29 & 13.8 \\
& Without & 181 & 86.2 \\
\hline Local Government Certification & None & 89 & 42.4 \\
& F \& B & 26 & 12.4 \\
& Business Permit & 95 & 45.2 \\
\hline
\end{tabular}

Table 2 shows that most of the Off-premises catering business have been in business for above ten years with 34.3 percent where they have considerable knowledge of the company's food safety practices. 1-5 years in service got 32.4 percent, 6-10 years with 29.0 percent, and only 9 caterers started business less than a year. Most of the catering businesses are self-operated with 71.4 percent. Through self-operation owners and management wanted to have a high-quality catering services using its own employees and management staff.

The total meals served per function ranges from 101-200 with 52.4 percent, above 20042.9 percent, below 100. 4.7 percent. The size of the meals served per day was ranging from 100 to 200 guests as it reflects on the number of staff they have and the capacity of the operation. The function per months usually happens 11-20 times with 54.8 percent; below 10 with 31.9 percent and above 20 with 13.3 percent. The increased demand for convenience, safe food and value also makes the catering an attractive option. Good service and quality foods are 
essential to the continued growth of the catering industry.

Birthdays are the usual events catered by them with 37.6 percent and the off-premises caterers are currently in demand during this event including seminar of 29.1 percent and wedding with 25.2 percent. These occasions are three of the most profitable events for caterers making these planned events into bonafide memories that truly require professionalism, quality and safe food including balance of elements into an exquisite celebration that people will enjoy most. Furthermore, 86.2 percent of the catering business did not receive food safety certification with only business permit as the local government certification they have complied with 13.8 percent. But these businesses can face various risks because of being not certified in food safety likewise many of them did not received local government certification and yet still providing food and beverage services. Food service establishment including off-premises catering business operation required food safety policies and procedures. Food businesses must conform to standard requirements to ensure that quality food and will not cause a food poisoning incident. Food poisoning outbreaks can have a devastating effect on a business, its staff and its customers. Almanza and Nesmith (2004) found that assessment of food safety knowledge require mandatory food safety certification in their state food codes though the outcome of the training is questionable.

\section{Table 3}

Food safety management practices of the off premise catering in terms of management operation

\begin{tabular}{|c|c|c|c|c|}
\hline \multicolumn{2}{|r|}{ Management operation on food safety } & Mean & VI & Rank \\
\hline 1. & Developed a food safety policy for the business and put it into action. & 3.10 & A & 4 \\
\hline 2. & $\begin{array}{l}\text { Have clear food safety procedures and policies that are performed and followed by } \\
\text { the employees }\end{array}$ & 3.17 & A & 1 \\
\hline 3. & $\begin{array}{l}\text { Include staff when planning ways to raise the importance of food safety in the } \\
\text { business. }\end{array}$ & 2.97 & A & 7 \\
\hline 4. & $\begin{array}{l}\text { Provided food safety training and orientation to employee before the start of their } \\
\text { job. }\end{array}$ & 2.95 & A & 8.5 \\
\hline 5. & Carry out independent risk assessments for priority food hazards. & 3.06 & A & 5 \\
\hline 6. & $\begin{array}{l}\text { Establish and foster global frameworks and mechanisms to ensure strategic } \\
\text { alignment and collaboration with other sectors, particularly the health }\end{array}$ & 2.99 & A & 6 \\
\hline 7. & $\begin{array}{l}\text { Perform internal audits on scheduled intervals to assess the effectiveness of the } \\
\text { food safety program. }\end{array}$ & 2.95 & A & 8.5 \\
\hline 8. & $\begin{array}{l}\text { Document the food safety risks and issues in the business, and check that control } \\
\text { measures are put in place and are working as planned }\end{array}$ & 3.15 & A & 2 \\
\hline 9. & $\begin{array}{l}\text { Appointed a food safety coach from within the business, for other team members } \\
\text { to approach. }\end{array}$ & 2.83 & A & 10 \\
\hline 10. & $\begin{array}{l}\text { Review safety performance and issues reports, and act on any emerging trends } \\
\text { before a problem comes up. Address any problems when they are identified from } \\
\text { reviewing performance. }\end{array}$ & 3.13 & A & 3 \\
\hline & $\begin{array}{ll}\text { Average } \\
\end{array}$ & 3.03 & A & \\
\hline
\end{tabular}

Scale. 3.50-4.00: Strongly Agree (SA); 2.50-3.49: Agree (A); 1.50-2.49: Disagree (D); 1.00-1.49: Strongly Disagree (SD).

Table 3 shows that off-premises catering employees unanimously agreed on the management operation on food safety of the business with the average mean of 3.03. They agreed that management operation on food safety have clear food safety procedures and policies that are performed and followed by the employees with 3.17 weighted mean.

Top in the rank of agreement is have clear food safety procedures and policies that are performed and followed by the employees (3.17), Document the food safety risks and issues in the business, and check that control measures are put in place and are working as planned (3.15) and review safety performance and issues reports, and act on any emerging trends before a problem comes up. Address any problems when they are identified from reviewing performance (3.13) It means that most of the catering business operations adhere to the clear safety procedures and policies that will serve as a guide for employees to act and perform based on it. Since they have the ultimate role of providing safe food to its customers. This was affirmed by Food Safety Act (2004), ensuring that employees of any food establishments must comply with health and hygiene procedures at food 
service, including safe practices for handling, preparing, storing, and serving food. Also, in the study of Pepple (2017), he emphasized there should be a mandatory requirement provided to enhance the employee knowledge on hygiene and safety issues. Food industry management should show the commitment to this course and work together with government and other regulatory bodies to avert the potential danger of outbreaks of food borne illness.

Next is employees document the food safety risks and issues in the business and check that control measures are put in place and are working as planned with 3.15. Documenting any issues involved in food safety is somewhat very crucial to combat possible consequences and anticipate problems to occur. The global safety resource indicates that documenting information and problem descriptions provides basis for actions to create formal process in which responsibility is assigned and workflows are clearly defined. More in-depth assessments can be afforded by root cause analysis, in which data is collected over time to identify trends and facilitate long-term solutions rather than a "quick fix" approach. This information should be communicated to everyone that is involved with the process, and they should understand their corrective responsibility.

The third in rank is to address any problems when they are identified from reviewing performance with 3.13 weighted mean. The management of these off-premises business are also compliant in the review of their safety performances that enable them to identify problems during the review and make their way to act before the problems occur. Proper reporting and documenting associated with developed food safety plans, quality management systems and auditing requires the organization and storage of large amounts of information and data. Truly, prompt access to all the data gathered is considered quite important in the process of documentation.

Least in rank are appointed a food safety coach from within the business, for other team members to approach (2.83), provided food safety training and orientation to employee before the start of their job (2.95) and perform internal audits on scheduled intervals to assess the effectiveness of the food safety program (2.95). For the managers, appointing somebody as a coach may entail another financial expense, in this sense, as they are doing a multi-function doing the same job description without necessarily having an official document as appointment. As a coach personnel, they are liable to prevent and alleviate food handling hazards for they have the authority to supervise and handle food at the premises to ensure safe food handling at all times.

As to safety food training, they believed in any food business is very vital in every employee; these trainings are considered barrier to some of the organization properly educating employees about best food safety practices. In the study of Şanlier et al. (2012) conducted in Turkey, he emphasized that most workers in catering industry have low level of knowledge on food safety, but by providing them a hygiene training the knowledge level increased, in the same idea where personal practices are needed to control disease, work on cleanliness, and do the supervision consistently. The study also explains the importance of education and training or experience in sanitation especially those food handlers who has a direct contact with food raw materials and finished products to wear suitable and hygienic clothing to maintain adequate cleanliness (Somwang et al., 2013).

Least items focused on agreement that many of the catering business in the study and perform internal audits on scheduled intervals to assess the effectiveness of the food safety program (2.95). Audits are a crucial component of maintaining food safety standards and certification, by providing transparency and assurance that standards are being maintained. This transparency increases the collaborative capacity of stakeholders across the supply chain, and enhances safety, efficiency, and continual improvement within individual organizations. Accountability must be inculcated among employees of the business and could be made by promoting clear goals, policies, training, and education. If employees will not be able to do their job well it is because they do not understand their specific functions and commitment to the organization. Hertzmanm (2007) shared his significant findings in his study that the performance of employees on food safety and sanitation is very important. They are aware of the proper procedures and knew it was necessary in the operation but failed to follow them during the execution of an event; it is very evident that they lack the sense of accountability.

Table 4 shows that all parameters have an agree verbal interpretation that indicates catering employees 
agreed to have all these personal practices were truly being practiced and applied by them with an average mean of 3.38. Top in the agreement are respondents showing enthusiasm and interest in food safety (3.50), they are also actively involved in making sure safe food (3.48) and demonstrate hygienic behavior in food preparation activities (3.48). Truly, the knowledge on the importance of personal hygiene immediately coincides with the adherence to personal hygiene practices. Employees who show enthusiasm and interest in food safety demonstrate their willingness to pay careful attention to even the smallest details conforming organizations safety practices.

\section{Table 4}

Food safety management practices of the off premise catering in terms of personal practices

\begin{tabular}{|c|c|c|c|c|}
\hline \multicolumn{2}{|r|}{ Personal Practices on Food Safety } & \multirow{2}{*}{$\begin{array}{c}\text { Mean } \\
3.35\end{array}$} & \multirow{2}{*}{$\frac{\mathrm{VI}}{\mathrm{A}}$} & \multirow{2}{*}{$\begin{array}{c}\text { Rank } \\
7\end{array}$} \\
\hline 1. & $\begin{array}{l}\text { Extend support with identifying hazards in the workplace and developing food } \\
\text { safety procedures. }\end{array}$ & & & \\
\hline 2. & $\begin{array}{l}\text { Put systems in place to communicate food safety and give regular feedback about } \\
\text { the food safety practices in the workplace and help improve them. }\end{array}$ & 3.30 & A & 9 \\
\hline 3. & $\begin{array}{l}\text { Include information on ways to communicate with management about food safety } \\
\text { issues and ideas.... }\end{array}$ & 3.39 & A & 6 \\
\hline 4. & Actively involved in making sure safe food. & 3.48 & A & 2 \\
\hline 5 . & $\begin{array}{l}\text { Spend time to attend meetings, site visits and training and actively contribute to } \\
\text { the business's food safety management practices }\end{array}$ & 3.10 & A & 10 \\
\hline 6. & Encouraged to provide suggestions for improving food safety practices & 3.34 & A & 8 \\
\hline 7. & Demonstrate hygienic behavior in a food preparation activity. & 3.48 & A & 2 \\
\hline 8 . & $\begin{array}{l}\text { Propose and demonstrate ways to promote a safe environment in the food } \\
\text { preparation area. }\end{array}$ & 3.40 & A & 5 \\
\hline & enthusiasm and interest in food safety. & $\begin{array}{l}3.50 \\
3.38\end{array}$ & $\begin{array}{c}\text { SA } \\
\text { A }\end{array}$ & 1 \\
\hline
\end{tabular}

Scale. 3.50-4.00: Strongly Agree (SA); 2.50-3.49: Agree (A); 1.50-2.49: Disagree (D); 1.00-1.49: Strongly Disagree (SD).

The overall agreement or mean rating mean of 3.38 means that the management is serious to invest in strategies that encourage food safety culture among their catering food service establishments. They believed how hygiene is paramount in dealing with food and with the catering industry rooted in this field, maintaining high hygienic standards is inevitable. This comes in handy in ensuring that they give their customers reliable and safe food. Moreover, food safety education should be provided among all food handlers, to improve their food safety knowledge (Lee, 2013). In food safety issues, various studies have reported that foodservice employees' poor food handling practices is one of the significant sources of food borne illness outbreaks. Ungku et al. (2013) poor personal hygiene, and cross contamination were identified as risk factors with the highest non-compliance rate. This might result to food poisoning outbreaks due to inability of the caterers to prioritize good practices like proper food handling, storing.

Meanwhile, the least weighted mean includes encouraged to provide suggestions for improving food safety practices (3.34), putting systems in place to communicate food safety (3.30), and give regular feedback about the food safety practices in the workplace and help improve them (3.10). The employee's participation in the issue of safety has long been warranted, their communication, suggestions and constant feedbacks needs to be heard as they are the one is making a big change in improving company's food safety practices.

Awareness on the proper usage and maintenance of kitchen tools and equipment are ways to avoid contamination to good food safety practice. Evans and Redmond (2016) clearly informed that the knowledge on storing process can improved or decreased incidence of food borne illnesses. Those materials and ingredients being used in food establishments required to also be correctly stored to maintain quality, inhibit damage and spoilage and eliminate cross-contamination because poor practice in storage can also pose either food specific hygiene hazards or general workplace hygiene risks. Likewise, unhygienic environment creates pest infestation and harborage. 
Castro, D.

Table 5

Test of difference in the safety practices to licensed and non-licensed off premise catering business

\begin{tabular}{lccccc}
\hline & Licensed & Non-licensed & $t$-value & $p$-value & Interpretation \\
\hline Management Operation & 3.1645 & 2.8886 & $3.576^{* *}$ & .000 & Significant \\
Personal Practices & 3.4291 & 3.3248 & 1.669 & .097 & Not Significant \\
\hline
\end{tabular}

Note. ${ }^{*} *$ Significant at $p$-value $<.01$ (two-tailed).

Table 5 presents the test of difference in the food safety practices and compliance between licensed and non-licensed off-premises catering business. There is a significant difference in scores on practices in terms of management operation between licensed and non-licensed off premise catering business as denoted by the computed $p$-value which is less than .01 alpha level. This signifies that the group of licensed off premise catering business has significantly higher response on practices of management operation compared to non-licensed. Moreover, no significant difference exists on personal practices as denoted by the computed $p$-value of .097 which is greater than .05 alpha level.

This signifies that their responses do not differ statistically, and they obtained varied responses between groups. Employees in licensed off-premises catering indicated to have more knowledge compared to the employees of non-licensed and that food safety practices were inadequately done. Since licensed off-premises catering will undergo series of food safety inspection, the researcher found it crucial and necessary to be compliant in different areas of food safety standards as mandate and making these practices as part of their daily tasks so that legal permit can be granted to the business. In the same case that these non-licensed found it unnecessary to get permit and can still operate without any legal permit then food safety is their least priority.

Likewise, there is a significant difference on compliance in terms of human and financial resources and environmental support as denoted by the computed $p$-values of both .009 which are less than .01 alpha level. This implies that the group of licensed off premise has significantly higher response on compliance in human and financial resources and environmental support compared to non-licensed. However, no significant difference exists on management style and system with computed p-value of .105 which is greater than .05 alpha level. This signifies that their responses on Management style and system do not differ statistically and they obtained varied responses between groups. They are both having the same good management system and style yet different in their way to support the business financially. Licensed off-premises caterers tend to provide employee training and supplies to support the effectiveness of their food safety program and to combat the frequent employee dilemmas. Sufficiency of resources was discussed by Ungku et al. (2013) as instrumental elements of environment support that influenced employees' food safety practices. During the interview of the researcher some participants confirmed that environment support not only facilitates, but also motivates employees to follow food safety practices.

\section{Table 6}

Proposed training plan for off-premises catering operation

\begin{tabular}{|c|c|c|}
\hline Key result area & Learning objectives & $\begin{array}{c}\text { Learning Methods / } \\
\text { Activities }\end{array}$ \\
\hline $\begin{array}{l}\text { Proactive regarding own } \\
\text { performance }\end{array}$ & $\begin{array}{l}\text { To demonstrate positive values in soliciting ideas and being receptive } \\
\text { to feedback and coaching, } \\
\text { To show confidence and dedication in identifying what needs to be } \\
\text { done and proactively seeking information and action in combating } \\
\text { problems and mistakes. } \\
\text { To reflect key responsibility and accountability for own actions, } \\
\text { learning and results. }\end{array}$ & $\begin{array}{l}\text { Interactive Learning } \\
\text { Face to face interaction } \\
\text { Video Presentation } \\
\text { Demonstration on actual } \\
\text { work situation }\end{array}$ \\
\hline $\begin{array}{l}\text { Adherence to positive attitude in } \\
\text { the workplace }\end{array}$ & $\begin{array}{l}\text { To demonstrate flexibility to adapt to different situations and problems } \\
\text { within the workplace like work pressure and lack of resources and } \\
\text { continue to deliver quality food and services. } \\
\text { To inculcate adaptability and works well without clear structures and } \\
\text { in ambiguous situations. }\end{array}$ & $\begin{array}{l}\text { Interactive Learning } \\
\text { Face to face interaction } \\
\text { Video Presentation } \\
\text { Demonstration on actual } \\
\text { work situation }\end{array}$ \\
\hline
\end{tabular}


Table 6 ... continued

\begin{tabular}{|c|c|c|}
\hline Key result area & Learning objectives & $\begin{array}{c}\text { Learning Methods / } \\
\text { Activities }\end{array}$ \\
\hline $\begin{array}{l}\text { Coping with Pressure } \\
\text { Adherence to positive approach } \\
\text { towards work }\end{array}$ & $\begin{array}{l}\text { To deliver a consistent and good approach and can be relied upon for } \\
\text { different situations. } \\
\text { To demonstrates patience and perseverance to work through tough } \\
\text { times and does not show frustrations when restricted or blamed. } \\
\text { To be able to apply self-discipline and have maintains a positive } \\
\text { approach at work and handles difficulties in a professional manner. } \\
\text { To show resiliency in coping with stress and pressure. }\end{array}$ & $\begin{array}{l}\text { Interactive Learning } \\
\text { Face to face interaction } \\
\text { Video Presentation } \\
\text { Demonstration on actual } \\
\text { work situation }\end{array}$ \\
\hline $\begin{array}{l}\text { The provision of personal } \\
\text { hygiene to expected standards }\end{array}$ & $\begin{array}{l}\text { To demonstrate and maintain high standards of personal hygiene. } \\
\text { To train employees to perform their jobs according to a specific } \\
\text { checklist that upholds food safety standards that will help reinforce the } \\
\text { specific level of detail needed to meet standards specifically in the } \\
\text { areas of health and hygiene requirements. } \\
\text { To assess the learners according to the required standard written in the } \\
\text { learning and development assessment checklist. }\end{array}$ & $\begin{array}{l}\text { Interactive learning: } \\
\text { Video presentation } \\
\text { Experiential learning } \\
\text { approach } \\
\text { On-the-job mentoring and } \\
\text { review }\end{array}$ \\
\hline $\begin{array}{l}\text { Maintaining a safe environment } \\
\text { for staff and customers }\end{array}$ & $\begin{array}{l}\text { Awareness of the different hazards. } \\
\text { To be able to minimize/ prevent cross contamination within a catering } \\
\text { business in the identified hazards. } \\
\text { Demonstrate how hazards are controlled through following correct } \\
\text { hygienic practices } \\
\text { 4. Deliver hazard analysis and control. }\end{array}$ & $\begin{array}{l}\text { Affective learning } \\
\text { Experiential Learning } \\
\text { approach } \\
\text { Demonstration } \\
\text { On-the-job mentoring and } \\
\text { review }\end{array}$ \\
\hline $\begin{array}{l}\text { Adherence to standards } \\
\text { procedures set to ensure the } \\
\text { safety }\end{array}$ & $\begin{array}{l}\text { To introduce employees and increase their understanding to the } \\
\text { standards of food safety. } \\
\text { Practice and demonstrate skills in the different key areas of } \\
\text { competency } \\
\text { To assess employees on food safety practices based on the standards in } \\
\text { the following areas of health and hygiene requirement, purchasing, } \\
\text { processing, packaging, display, serving, food disposal, maintenance } \\
\text { and pest management. } \\
\text { Describe corrective actions that can be taken when food safety } \\
\text { standards are not followed. }\end{array}$ & $\begin{array}{l}\text { Affective exercises through } \\
\text { lectures and case studies } \\
\text { Brainstorming } \\
\text { In-house training } \\
\text { Demonstration } \\
\text { One day Immersion training } \\
\text { Off-site visitation } \\
\text { On-the-job mentoring and } \\
\text { review }\end{array}$ \\
\hline Adhere to food safety standards & $\begin{array}{l}\text { To actively participates in training related to their specific role. } \\
\text { To deliver consistent acts in accordance with the existing food safety } \\
\text { requirements. } \\
\text { To demonstrate diligence and compliance with organizational } \\
\text { standards and procedures. } \\
\text { To recognize the need for a good work environment which is free from } \\
\text { hazards and follows policies and procedures with respect to health and } \\
\text { safety. }\end{array}$ & $\begin{array}{l}\text { Affective exercises } \\
\text { Experiential learning } \\
\text { Demonstration } \\
\text { Offsite visitation }\end{array}$ \\
\hline $\begin{array}{l}\text { Benchmarking the gap between } \\
\text { existing food safety system and } \\
\text { the food safety standards. }\end{array}$ & $\begin{array}{l}\text { To document possible barriers to implementation of good food safety } \\
\text { practices among food handlers } \\
\text { To deliver corrective actions when tasks found to be uncontrollable. }\end{array}$ & $\begin{array}{l}\text { Discussions } \\
\text { Coaching and mentoring } \\
\text { Simulation and } \\
\text { Demonstration }\end{array}$ \\
\hline
\end{tabular}

Food safety training is an important task of every food business in ensuring food safety. It is a legal requirement that food handlers are supervised and trained in food safety matters commensurate with their work activity. Training is only effective when the training standards are being demonstrated and met in the food operation. The proposed training plan is the primary step in the development of a food safety training program. It provides the mandate for the program and establishes its goals and competencies. The training plan serves as a tool to assess employee competency and ability to deliver the required outcomes based on the food safety standards. This will also be consisting of a checklist that provides a systematic approach to the identification of food safety practices that must be maintained and observed during food service operation specifically from purchasing of food raw materials, processing, serving, packaging, transporting and holding.

\section{Conclusion and recommendations}

The off-premises catering business operations in Occidental Mindoro employed performance work team mostly males and young individuals with experienced not less than one year and have complementary skills who collaborate, innovate and produce safe food. The off-premises catering business operations in Occidental can face various risks because of non-compliance to food safety certification assessed by the certified auditor. The employees of off-premises catering between licensed and non-licensed business operation demonstrated consistent knowledge on food safety such as health and hygiene requirement, maintenance and pest management but failed to follow from required standards in off-site operations. The evaluation of food safety practices among 
different caterers determined the specific safety programs and interventions they could applied in their own catering business operation. The researcher was able to propose an action plan.

The researcher proposed series of recommendations: To improve food safety practices, local authorities need to have an annual audit of the practices and require extensive certification requirements. The management of off-premises catering business operation may focus their efforts and commitment on food safety and recruitment process to ensure employees who have a strong work ethics. The propose food safety training plan developed in this study are based on the existing food safety standards that may be used by the regulatory professionals in auditing food safety compliance of food service including catering business where inspection results can serve as an opportunity for food safety promotion, education and food safety performance. Universities/colleges offering hospitality and food service subjects may align their curriculum on food safety for off-premises catering business. And finally, future studies may focus on the development and evaluation of new approaches to investigate potential interventions resulting into sustained food hygiene compliance and to respond to complexity of the catering business.

\section{References}

Almanza, B. A., \& Nesmith, M. S. (2004). Food safety certification regulations in the United States. Journal of Environmental Health, 66(9), 10-14.

Evans, E. W., \& Redmond, E. C. (2016). Older adult consumer knowledge, attitudes and self-reported storage practices and ready-to-eat of food products and risks associated with listeriosis. Journal of Food Protection, 79(2), 263-272. https://doi.org/10.4315/0362-028X.JFP-15-312

Hertzman, J. L. (2007). Identifying the characteristics of and quality indicators for associate degree culinary programs: A survey of educators and industry (Dissertation Abstracts International 67/07) [Doctoral dissertation, University of Nevada Las Vegas].

Karaman, C. F., Tunalioglu, R., \& Ova, G. (2012). Barriers and benefits of the implementation of food safety management systems among the Turkish dairy industry: A case study. Food Control, 25(7), 732-739. https://doi.org/10.1016/j.foodcont.2011.11.041

Lee, B. (2013). Food safety interventions: A review of food safety interventions and evaluation in food service establishments national collaborating center for environmental health at the British Columbia centre for disease control. BC.

Manning, L. (2018). The value of food safety culture to the hospitality industry. Worldwide Hospitality and Tourism Themes. https://doi.org/10.1108/WHATT-02-2018-0008

Neil, J. A., Binkley, M., \& Henroild, D. (2013). Assessing factors contributing to food safety culture in retail food establishments [University of Houston].

Pepple, N. (2017). Environment and food poisoning: Food safety knowledge and practice among food vendors in Garki, Abuja. Nigeria Journal of Health Education Research Development, 5(217). https://doi.org/10.4172/2380-5439.1000217

Şanlıer, N., Bilici, S., Çelik, B., \& Memiş, E. (2012). Food safety knowledge and practices of nursing students. Italian Journal of Food Science, 24(7), 1-8.

Somwang, C., Charoenchaichana, P., \& Polmade, M. (2013). The implementation of good manufacturing practice (GMP) system in the poultry industry: A case study of hatching in Slatter, J. (2006). ISO 22000 for modern management. Food hygiene, 17(3).

Strohbehn Food Protection Trends. (2014). Volume 34, No. 3, p. 139-150.

Ungku, E. (2013). Measuring food safety culture: Insights from onsite foodservice operations [Graduate Theses and Dissertations]. http://lib.dr.iastate.edu/etd/13145

Yardımcı1, G. H., Çakiroğlu1, F. P., \& ÖzferÖzçelik, A. (2015). Hygiene knowledge of food staff in catering industry: A sample from Turkey. 